\title{
ANÁLISIS DEL ÍNDICE DE ACCIDENTABILIDAD EN LA AVENIDA MARISCAL SUCRE, ENTRE LAS AVENIDAS, UNIVERSITARIA Y SAN FRANCISCO DE RUMIHURCO.
}

\section{Analysis of the accident rate on Avenida Mariscal Sucre, between the Avenues Universitaria and Avenida; San Francisco de Rumihurco.}

Rivera Alex I. (D), León Mario G.* iD, Cabezas Juan F. iD, Miranda Stalin J.

Universidad Central del Ecuador, Facualtad de Ingeniería y Ciencias - Ingeniería Civil, Quito, Ecuador.

*mgleon@uce.edu.ec

$\mathrm{R}$ esumen

En el presente estudio técnico el tema de accidentabilidad es abordado de manera estadística a nivel nacional, provincial y cantonal, para posteriormente enfocarse en la avenida Mariscal Sucre la cual mediante datos de la Empresa Pública Metropolitana de Movilidad y Obras Púbicas es la vía más accidentada dentro del sistema vial del Distrito Metropolitano de Quito. La avenida Mariscal Sucre tiene una longitud de 31 kilómetros atravesando la ciudad por su flanco occidental desde Guamaní en el sur hasta Ponceano en el norte, para su estudio se delimitó el recorrido tomando como punto de inicio la intersección con la avenida Universitaria hasta la avenida San Francisco de Rumihurco resultando un tramo de 12.7 kilómetros. El análisis del tramo de la avenida parte de la determinación de los índices de accidentabilidad, morbilidad y mortalidad mediante el estudio del Trafico Promedio Diario Anual (TPDA) y de un buffer poblacional de los barrios que colindan con el trayecto de la vía. Posteriormente se procede a identificar los puntos críticos también conocidos como negros que son aquellos donde los siniestros son más recurrentes.

Palabras claves: Mariscal Sucre, accidentalidad, índices, mortalidad, buffer, percentil.

\section{A bstract}

In this technical study, the subject of accident rate is approached statistically at the national, provincial and cantonal levels, to later focus on Mariscal Sucre avenue which, according to data from the Metropolitan Public Company of Mobility and Public Works, is the road most rugged within the road system of the Metropolitan District of Quito. Mariscal Sucre avenue has a length of 31 kilometers crossing the city on its western flank from Guamani in the south to Ponceano in the north, for its study the route was delimited taking as a starting point the intersection with Avenida Universitaria to Avenida San Francisco de Rumihurco, resulting in a 12.7 kilometer stretch. The analysis of the section of the avenue starts from the determination of the accident, morbidity and mortality rates through the study of the Annual. Average Daily Traffic (ADT) and a population buffer of the neighborhoods that adjoin the route of the road. Subsequently, the critical points also known as black are identified, which are those where the claims are most recurrent, in these points a study of point speeds will be carried out to obtain the 85th percentile that allows identifying the points with the highest traffic speed.

Keywords: Mariscal Sucre, accident rate, rates, mortality, buffer, percentile.

Fecha de recepción: 05-04-2021

Fecha de aceptación: 08-11-2021

Fecha de publicación:

\section{INTRODUCCIÓN}

El número anual de víctimas fatales resultado de accidentes de tránsito a nivel mundial ha sufrido un incremento de 1.20 a 1.35 millones durante los años 2015 y 2016, además esta causa de muer- 
te se ha posicionado como la principal en las personas de entre los 15 y 29 años (1). La distribución de las víctimas causadas por los accidentes de tránsito es irregular en todo el mundo y depende del desarrollo de cada país, en los países de bajos ingresos estas muertes representan el $90 \%$ de las que se producen en todo el mundo a pesar de que en dichos países solo se encuentra el 50\% del total de vehículos del mundo (2).

Después del impacto en la salud pública, los accidentes de tránsito se convierten en un problema importante para el desarrollo, significando una pérdida económica equivalente al 3\% del PIB en países industrializados y $5 \%$ en países de ingresos medios y bajos (3) como es el caso de los países de América Latina y el Caribe (ALC) en donde está perdida económica es inaceptable pues podría invertirse en el mejoramiento de la calidad de vida y oportunidades para las personas (4).

En el 2011 las Naciones Unidas a través de la OMS proclamaron el Decenio de Acción para la Seguridad Vial (2011 -2020) con el objetivo de estabilizar y reducir el número de muertes producto del tránsito a nivel mundial mediante 5 pilares básicos; gestión de la seguridad vial, vías de tránsito y movilidad, vehículos más seguros, usuarios de vías de tránsito y respuesta tras los accidentes (5).

A pesar de los objetivos planteados por la OMS las estadísticas muestran una tendencia al aumento de los accidentes de tránsito, algo que se evidencia en América Latina con un total anual de 142525 fallecidos y 5 millones de lesionados. En cuanto a los peatones fallecidos por accidentes de tránsito, el promedio para la subregión Andina representa el 43\%, mientras que Ecuador ocupa el séptimo lugar en tasa de mortalidad por accidentes de tránsito en Latinoamérica y es el décimo tercero a escala global en comparación con países de ingresos similares (2).

Un accidente de tránsito es un hecho o situación ocurrido en la vía donde interviene por lo menos un vehículo en movimiento que puede o no provocar lesiones y/o muertes a personas así como daños materiales [6], es un evento que escapa del control del ser humano aunque esto no significa que sea un hecho súbito potencialmente prevenible (7), es por esta razón que la OMS y Naciones Unidas hacen uso de la frase "la seguridad vial no es accidental" lo que da como resultado que la denominación de accidente de tránsito debería ser reemplazada por "siniestro o hecho vial” (8).

Según la tipología a los siniestros de tránsito se los pude considerar: simples cuando únicamente involucran a un solo vehículo que se encuentra en movimiento sobre la vía el cual puede experimentar perdida de pista, volcamiento, salto, caída, incendio, estrellamiento y/o rozamiento; múltiples en los que intervienen dos o más vehículos simultáneamente o bien intervienen vehículos y peatones, estos pueden resultar en choques, atropello, arrollamiento, roce y/o colisión, la última tipología recae en los accidentes mixtos que se definen como siniestros en los que se combinan varios tipos de accidentes de tránsito pudiendo ser simples con múltiples o viceversa (6).

Giscard, indica en su estudio que el 61\% de conductores interrogados señalan al destino o a la mala suerte como el principal factor desencadenante de un siniestro de tránsito, si esta visión fatalista fuera cierta, las medidas que se toman para prevenir accidentes de tránsito serian inútiles ya que estos tendrían lugar cuando y donde menos se lo espera (9). Los siniestros de tránsito son producto de cuatro factores fundamentales que tienen una interacción constante en un lugar y tiempo determinado (10), estos son: el factor humano, factor mecánico que se refiere al vehículo automotor, factor vial o características geometrías de la vía y el factor ambiental. (Tabla 1)

\begin{tabular}{cc}
\hline Factor & Participación \\
\hline Vía y entorno & $\underline{2.5 \%}$ \\
\cline { 2 - 3 } Usuario & $65.0 \%$ \\
\hline Vehículo & $2.5 \%$
\end{tabular}

Tabla 1. Participación de los factores del tránsito en los siniestros viales. Fuente: (10)

El desarrollo de un siniestro de tránsito está presidido por dos elementos "tiempo" y "espacio", el espacio es el lugar específico donde suceden los hechos, mientras que el tiempo corresponde a segundos o fracciones de segundos que a la vez se componen de tres fases, percepción, decisión y conflicto. (Figura 1) 


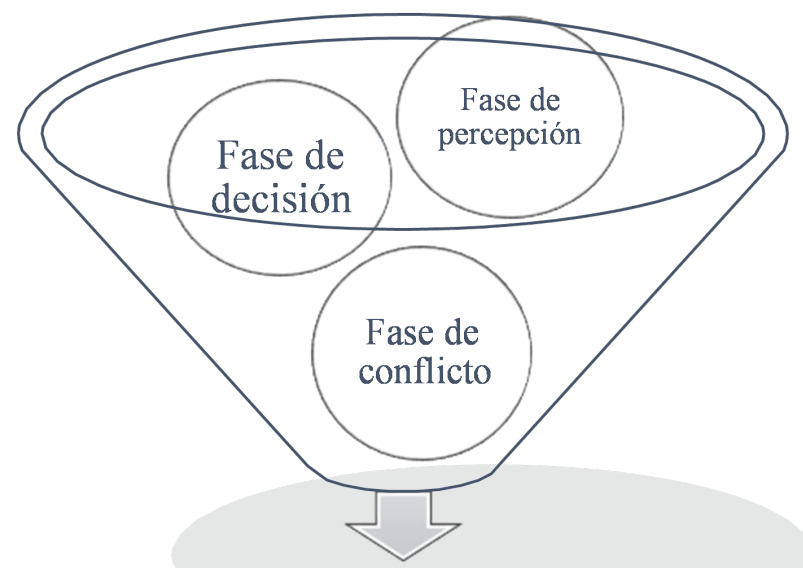

Evolucion del accidente

Figura 1. Fases de un accidente de tránsito.

\section{MATERIALES Y MÉTODOS}

Para el estudio se ha recurrido a la aplicación del método empírico-analítico y el método deductivo directo, debido a que se extraen partes de un todo para ser analizadas individualmente mediante el procesamiento y estudio de datos entregados por entidades públicas y por trabajos realizados en campo, conduciendo la trayectoria del estudio de lo general a lo particular.

El índice de accidentabilidad en la Avenida Mariscal Sucre ha sido el tema general de estudio y de ello se han desglosado varias partes que fueron analizadas individualmente como las causas, por las cuales se producen los accidentes de tránsito, la tipología y lugares de los siniestros.

\section{Análisis de accidentalidad: Ecuador y Distrito Metropolitano de Quito.}

El registro de siniestros de tránsito de manera oficial por parte de las entidades reguladoras ha permitido la realización de estudios que conllevan el análisis de la accidentalidad vial como el titulado "Caracterización de la mortalidad por Accidentes de Tránsito en Ecuador, 2015" del cual se desprende que desde 1998 al 2015 fallecieron 29148 personas debido a algún tipo de siniestro vial (11).

De acuerdo a los datos expuestos por la Agencia Nacional de Tránsito a escala nacional el número de siniestros viales, así como la cantidad de lesionados producto de estos sucesos ha experimen- tado una disminución desde el año 2015 al 2019 como se aprecia en la Figura 2.

A pesar de que el número de incidentes de tránsito ha disminuido, la cifra de víctimas fatales correspondiente al mismo periodo presenta un incremento de 2138 a 2180 lo que permite entrever que la gravedad de los accidentes se ha agudizado.

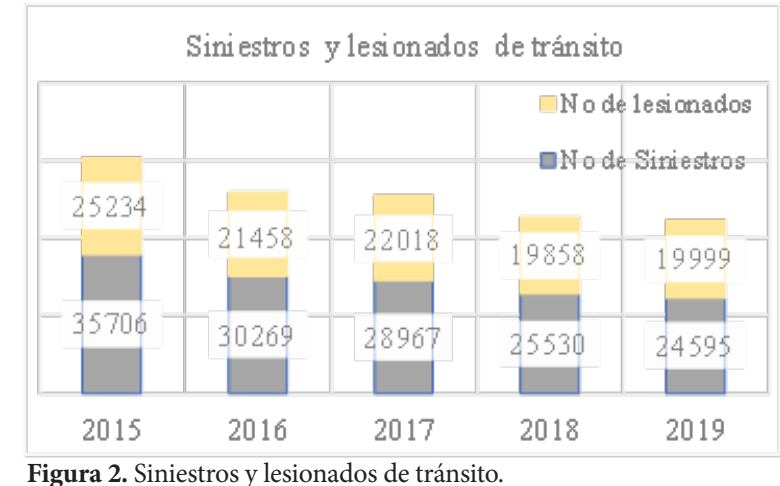

La pandemia actual causada por el COVID-19, ha obligado a la sociedad a integrarse a una nueva realidad la que incluye una movilidad totalmente alterada debido al confinamiento, el teletrabajo y principalmente por las diferentes restricciones vehiculares impuestas a nivel nacional como medidas de control ante el avance de la pandemia (12), todo esto ha dado paso a un impacto directo en las estadísticas relacionadas con los siniestros de tránsito (13), evidenciándose una disminución promedio del $36 \%$ en el número de siniestros, lesionados y fallecidos correspondientes a los meses de enero a septiembre del 2020 en comparación con el mismo periodo del año 2019.

A nivel nacional la causa a la que se atribuye el $24 \%$ de siniestros es la distracción al momento de conducir debido al uso del teléfono celular y otros dispositivos electrónicos como pantallas acopladas al tablero del automóvil, mientras que al exceso de velocidad en conjunto con el desdén hacia las señales de tránsito representan cada una el $16 \%$ como causa generadora de accidentes. La provincia de Pichincha ha experimentado una reducción del número de accidentes en un $68 \%$ en el 2019 con respecto al año 2015, dándose una concentración del 95\% del total de siniestros solo en el Distrito Metropolitano de Quito. (Figura 3) 


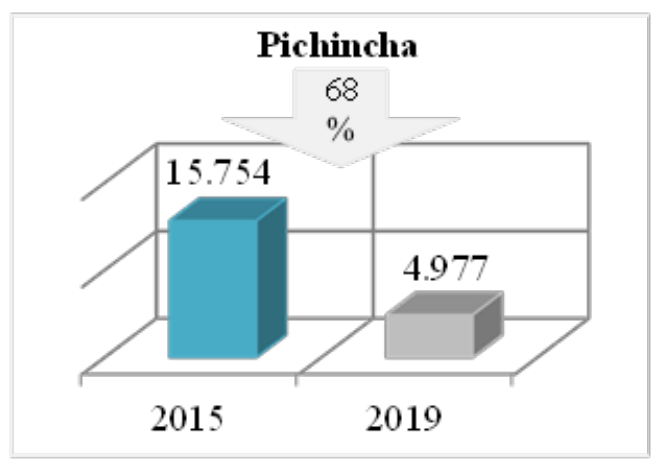

Figura 3. Accidentes de transito sucitados en la provincida de Pichincha.

Análisis de accidentalidad en la Avenida Mariscal Sucre

La Avenida Mariscal Sucre, también conocida como Avenida Occidental fue idealizada por el alcalde de Quito Sixto Durán Ballen y construida en el año de 1976 con el objetivo de descongestionar el tránsito del centro de la urbe, en un inicio esta Avenida formaba parte del anillo vial periférico de la ciudad de Quito (14), pero a medida que la expansión poblacional avanzaba, esta perdía su propiedad delimitadora pasando a convertirse en la actualidad en una vía Semi Expresa Arterial.

La Avenida Mariscal Sucre alberga la mayor cantidad de accidentes en comparación con el resto de vías urbanas principales del DMQ (15) como se aprecia en la Figura 4, lo que justifica el actual estudio destinado a la identificación de los puntos críticos en un tramo de $12.7 \mathrm{~km}$ que inicia desde la Av. Universitaria al Sur hasta la Av. San Francisco de Rumihurco al Norte.

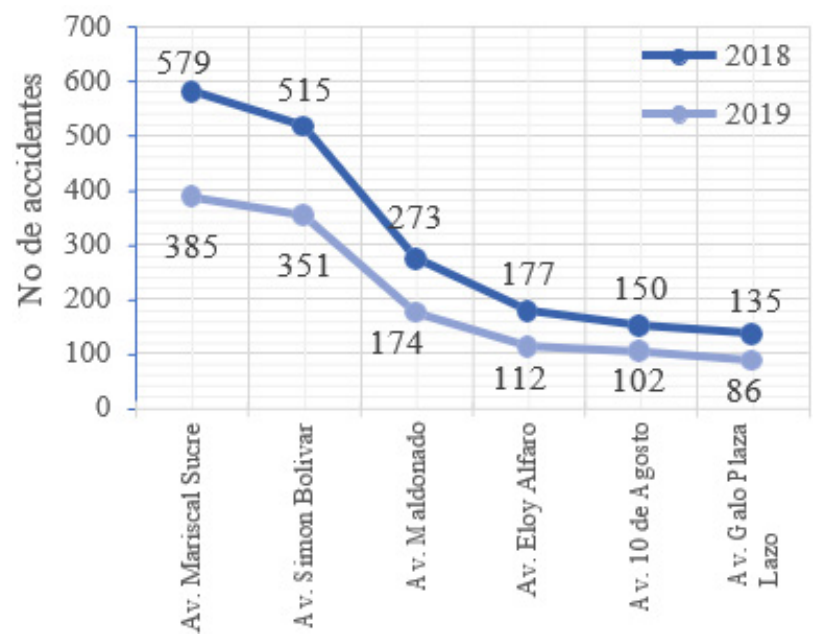

Figura 4. Número de accidentes en las principales Avenidas del D.M.Q

Como ya se dijo anteriormente todos los acciden- tes de tránsito son prevenibles y evitables incluso los que son atribuidos a fallas de fabricación de vehículos pues mediante estudios se ha verificado que estas son producto de un error humano consciente, es por eso que solo es posible hablarse de eventos inevitables a los que involucran en su totalidad a la intervención de la naturaleza. Partiendo de lo anterior descrito es posible decir que en un incidente de tránsito existe la participación directa de conductores y peatones, mediante el análisis llevado a cabo de los datos estadísticos correspondientes a los años 2018 y 2019 de la Av. Mariscal Sucre se establece un porcentaje de participación directa de los conductores del 94\% y $6 \%$ por parte de los peatones.

Aunque a nivel nacional el exceso de velocidad se posiciona como la segunda causa generadora de siniestros de tránsito, en la Av. Mariscal Sucre pasa a ser la causa principal, esto a pesar que desde el punto de vista teórico la velocidad tiene un efecto positivo sobre la movilidad pues reduce los tiempos de transporte, la realidad demuestra que tiene repercusiones negativas para la seguridad en las vías ya que incrementa la probabilidad de ocurrencia de accidentes, así como la gravedad de sus consecuencias (3).

La infraestructura vial compuesta por la superficie de la carretera o calzada y la señalización horizontal y vertical, es un factor importante de seguridad vial, en el que el diseño de la carretera influye directamente en el número de siniestros que puedan darse a lo largo de esta (16).

A pesar de que en la fase de diseño se prioriza la seguridad vial, es inevitable que durante la operación de la vía se registren siniestros viales, pudiéndose dar estos de manera dispersa a lo largo de la carretera o concentrándose en ciertos puntos específicos que reciben el nombre de "puntos críticos o negros".

La importancia de ubicar los "puntos negros" radica en la posibilidad de evaluación e identificación de las posibles causas técnicas que originan el alto número de siniestros, para de esta manera proponer medidas correctivas acordes a cada situación que tendrán la finalidad de reducir la siniestralidad de los puntos y por ende las conse- 
cuencias que se derivan de estos (17). En el tramo de la Avenida Mariscal Sucre objeto de estudio ha sido posible identificar cinco puntos críticos en los que el número de siniestros ha aumentado o se ha mantenido constante. (Tabla 2)

\begin{tabular}{|c|c|c|}
\hline \multirow[t]{2}{*}{ Punto } & \multicolumn{2}{|c|}{$\mathrm{N}$ de siniestros } \\
\hline & 2018 & 2019 \\
\hline Mariana de Jesús & 18 & 13 \\
\hline N48 (subida al Pinar) & 7 & 7 \\
\hline Cesar Villacres & 12 & 8 \\
\hline Fernández Salvador & 25 & 14 \\
\hline José Figueroa & 1 & 4 \\
\hline
\end{tabular}

Tabla 2. Participación de los factores del tránsito en los siniestros viales.

Con la finalidad de sintetizar de manera analítica los aspectos más importantes que intervienen en la siniestralidad de la Avenida Mariscal Sucre se obtendrán indicadores cuya función radica en la cuantificación de los siniestros (18). Los índices que se muestran a continuación fueron construidos especialmente para el tramo de la vía estudiado, pues tienen como base numérica, al Tráfico Promedio Diario Anual (TPDA) de la vía, un buffer poblacional de los barrios colindantes a esta y además de datos estadísticos relevantes que cuantifican la participación que han tenido los conductores y peatones en los siniestros registrados. (Figura 5)

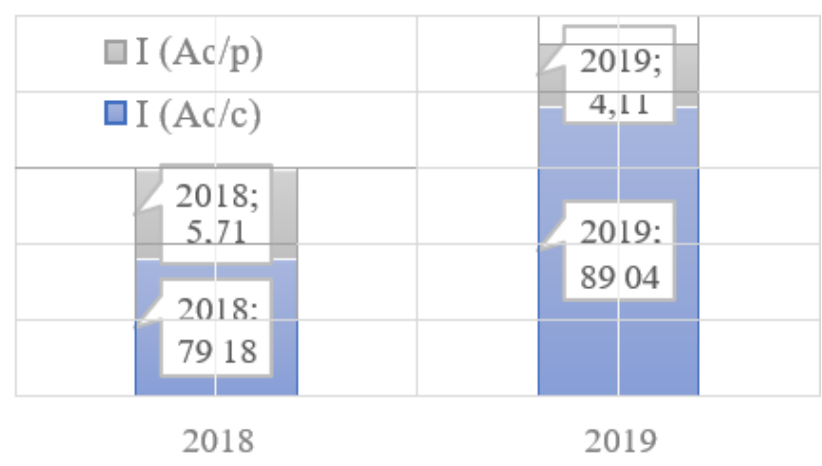

Figura 5. Indicadores de accidentes causados por el conductor y peatón.

Para que exista una reducción en los índices de accidentalidad, es indispensable que los usuarios de la vía siendo estos conductores, peatones o pasajeros dispongan oportunamente de información suficiente que les permita usar adecuadamente las vialidades, lo que se logra a través de señales de tránsito estandarizadas que permitan a los usuarios una interpretación uniforme de la información que estas transmiten a lo largo de una vía ya sea rural o urbana (19).

Los dispositivos de control de tránsito indican a los usuarios las precauciones o prevenciones que deben tener en cuenta, las restricciones existentes en el tramo de la vía por el que se está circulando y la información necesaria sobre aspectos que necesariamente debe conocer el usuario de la vía, razones por las cuales la señalización vial está ligada directamente a la función de evitar siniestros viales, motivo suficiente por el cual en las vías debe verificarse periódicamente el estado físico, visibilidad y necesidad de nueva señalización. La fotogrametría al ser una extensión de la fotografía aérea, permite obtener información visual mediante vehículos aéreos no tripulados, que siguen una trayectoria definida previamente denominada "plan de vuelo" el cual está compuesto de una sucesión de hitos o puntos definidos geográficamente mediante latitud y longitud que el vehículo sobrevolará para la obtención de imágenes (20). En la Avenida Mariscal Sucre, mediante fotogrametría se pudo constatar el estado del inventario vial existente en la actualidad en cada punto crítico, esto con la finalidad de poseer información que permita tomar medidas destinadas al mejoramiento de dicho inventario y por ende influir directamente en la disminución de los siniestros viales.

\section{RESULTADOS Y DISCUSIÓN}

Desde el año 2015 el número de siniestros a nivel nacional ha experimentado en promedio una disminución anual del 9\% hasta el año 2019, mientras que debido a las restricciones de movilidad impuestas en el territorio nacional como medida para controlar el avance del Covid-19 durante el 2020 el número de siniestros se redujo en un $37 \%$ (21).

A nivel provincial, Pichincha y Guayas son las provincias más afectadas por los siniestros viales, pues abarcan el mayor número de estos, aunque existe una marcada diferencia entre las dos como se aprecia en la Figura 6, a medida que en la provincia de Pichincha desde el 2015 el número de siniestros presenta una tendencia a disminuir, en el Guayas el número ha ido en ascenso, hasta que 
en el año 2018 desplazo a Pichincha y paso a ser la provincia con más siniestros a nivel nacional.

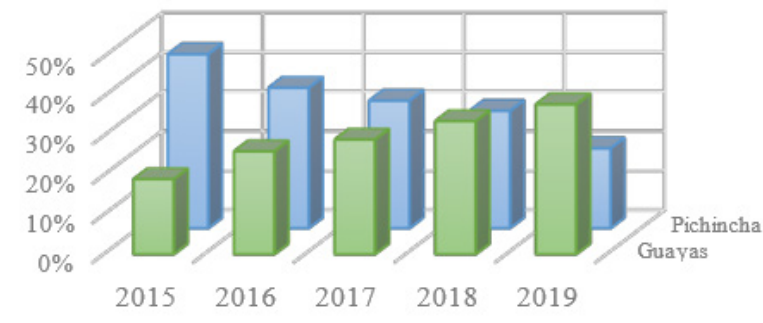

Figura 6. Porcentaje de accidentes de tránsito en las Provincias de Pichincha y Guayas.

En la provincia de Pichincha el distrito Metropolitano de Quito es el cantón con mayor número de siniestros, concentrándose gran parte de estos en la Avenida Mariscal Sucre. Mediante un estudio estadístico se identificaron los Puntos Críticos en el tramo norte de la Avenida desde la intersección con la Avenida Universitaria hasta la Avenida San Francisco de Rumihurco, esto permitió su posterior análisis con el objetivo de tomar medidas destinadas a la reducción de siniestros viales.

La fotogrametría permite estudiar zonas geográficas a partir de imágenes enlazadas entre sí, con el fin de extraer información útil para aplicarla a diferentes fines tales como la inspección de estructuras, el ordenamiento urbano y vial, etc. Gracias a la fotogrametría fue posible cubrir el área estudiada en cada punto, facilitando la distinción de la señalización horizontal y puntos de iluminación, destacando tramos con desgaste en la pintura en la señalización. (Figura 7)

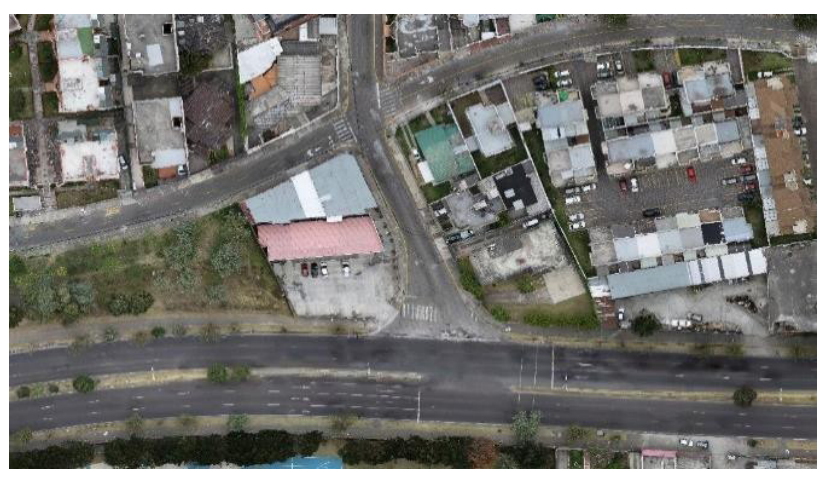

Figura 7. Avenida Mariscal Sucre y calle $N^{\circ} 48$.
Demarcar las señales horizontales ayuda con la seguridad del usuario en la vía, como, por ejemplo; el paso cebra, (importante para el cruce peatonal), líneas de borde de calzada, (destinada para que el conductor observe el trayecto de la vía), líneas de división de carril, (adecuadas para distribuir a los vehículos de forma ordenada en el carril deseado), simbología (eficiente para direccionar al vehículo), etc. Es por ello que se debe garantizar una señalización horizontal legible y adecuada pues la ineficiente demarcación trae como consecuencia que los carriles sean invadidos o no sea posible distinguir la línea borde de la calzada provocando pérdida de pista, que los vehículos no se detengan en las líneas de pare, o circulen en carriles de dirección opuesta, etc. causas que a menudo provocan accidentes en esta vía.

Dentro del sistema vial, la seguridad del usuario sea este peatón o conductor, requiere de la visibilidad necesaria para incorporarse al flujo vehicular o peatonal, en este punto es donde la iluminación artificial tiene un papel importante, pues a pesar de que la carga vehicular durante la noche es un tercio de la existente en el día, los siniestros ocurren en mayor proporción en horas nocturnas, por lo cual, analizar la correcta ubicación de los puntos de iluminación es trascendental para que los usuarios viajen con seguridad por la vía.

\begin{tabular}{|c|c|c|c|c|}
\hline Punto Crítico & \multirow{2}{*}{$\begin{array}{l}\text { Radio de } \\
\text { curvatura }\end{array}$} & \multirow{2}{*}{$\begin{array}{l}\text { Espaciamiento } \\
\text { máximo } \\
\text { (INEN) }\end{array}$} & \multirow{2}{*}{$\begin{array}{l}\text { Distancia } \\
\text { en el } \\
\text { proyecto }\end{array}$} & \multirow[b]{2}{*}{ Observación } \\
\hline \multirow{2}{*}{ Av. Mariscal Sucre y } & & & & \\
\hline & $\mathbf{m}$ & $\mathbf{m}$ & $\mathbf{m}$ & \\
\hline \multirow{2}{*}{ Mariana de Jesús } & \multirow{2}{*}{208.75} & \multirow{2}{*}{55} & 50 & Cumple \\
\hline & & & 30 & Cumple \\
\hline N 48 & 439.37 & 77 & 50 & Cumple \\
\hline César Villacrés & 2216.94 & 95 & 40 & Cumple \\
\hline \multirow{2}{*}{$\begin{array}{l}\text { Fernández } \\
\text { Salvador }\end{array}$} & \multirow[b]{2}{*}{ - } & \multirow{2}{*}{95} & 30 & Cumple \\
\hline & & & 40 & Cumple \\
\hline José Figueroa & 384.58 & 72 & 50 & Cumple \\
\hline
\end{tabular}

Tabla 3. Iluminación actual en los Puntos Críticos

Como se observa en la Tabla 3 los puntos de iluminación han sido colocados a la distancia recomendada por el Instituto Ecuatoria de Normalización. 
Las avenidas y calles son uno de los principales componentes del sistema vial, sujetos a volúmenes de tránsito que poseen características espaciales y temporales específicas. Su principal objetivo es obtener información sobre el movimiento de vehículos dentro de un sistema vial y son expresados siempre con respecto al tiempo esto hace posible que sea estudiado su comportamiento futuro. De forma general los datos de volúmenes de tránsito se utilizan en diferentes campos, tales como planeación, ingeniería de tránsito, investigación, uso comercial y seguridad. El volumen de tránsito obtenido en el presente proyecto estará destinado al campo de seguridad vial, permitiendo el cálculo del índice de accidentes y mortalidad con respecto al Tráfico Promedio Diario Anual, el cual es un dato importante para ratificar la factibilidad del estudio. Para la obtención del TPDA y la composición vehicular correspondiente a la Avenida Mariscal Sucre, se aplicó dos tipos conteos el manual y el automático.

El conteo automático permite obtener el volumen total del tráfico de manera rápida y sin distinción entre cada vehículo debido a la limitada tecnología de los contadores automáticos, por lo cual no pueden ser considerados como suficientes para un estudio de seguridad vial, para solventar esta falencia se aplica el conteo manual que permite conocer el porcentaje de vehículos livianos, pesados y buses que circulan por la vía, y que se muestra a continuación en las Tablas 4 y 5 .

\begin{tabular}{|c|c|c|c|c|c|c|c|c|}
\hline PUNTO & SENTIDO & TPDS & FH & FD & FS & MES & FM & $\begin{array}{c}\text { TPDA } \\
\text { (Veh/dia) }\end{array}$ \\
\hline $\begin{array}{c}\text { Av. } \\
\text { LEGARDA }\end{array}$ & Norte - Sur & 36109 & 1.00 & 1.006 & 1.00 & ENERO & 1.031 & 37443 \\
\hline $\begin{array}{c}\text { Sur }- \text { Norte } \\
\text { Av. }\end{array}$ & 38272 & 1.00 & 1.009 & 1.00 & ENERO & 1.031 & 39827 \\
$\begin{array}{c}\text { MARIANA } \\
\text { DE JESUS }\end{array}$ & Sur - Nur & 21220 & 1.00 & 1.041 & 1.00 & ENERO & 1.031 & 22783 \\
\hline
\end{tabular}

Tabla 4. Valor de TPDA (contadores automáticos).

\begin{tabular}{|c|c|c|c|c|c|c|}
\hline PUNTO & SENTIDO & Livianos & Pasajeros & Carga & Motos & TPDA \\
\hline \multirow{4}{*}{$\begin{array}{l}\text { Av. } \\
\text { Mariscal } \\
\text { Sucre y } \\
\text { Legarda }\end{array}$} & \multirow{2}{*}{ Norte - Sur } & 33051 & 607 & 752 & 1682 & 36092 \\
\hline & & $91.57 \%$ & $1.68 \%$ & $2.08 \%$ & $4.66 \%$ & $100.00 \%$ \\
\hline & \multirow{2}{*}{ Sur - Norte } & 33941 & 792 & 715 & 2559 & 38007 \\
\hline & & $89.30 \%$ & $2.08 \%$ & $1.88 \%$ & $6.73 \%$ & $100.00 \%$ \\
\hline
\end{tabular}

Mediante el valor del TPDA fue posible realizar la reclasificación de la Avenida Mariscal Sucre la cual en su inicio fue concebida como una vía perimetral, y en la actualidad según la Ordenanza Metropolitana $\mathrm{N}^{\circ} 0432$ (2013) entra en la clasifi- cación de vía semi expresa arterial.

\section{Alternativas de solución}

Con el objetivo de lograr vías urbanas seguras para los usuarios se necesita intervenir en dos ámbitos principalmente:

Preventivo: en el que se busca evitar que se generen conflictos y por lo tanto siniestros viales, en este ámbito se encuentra la aplicación de criterios de seguridad aplicados en la planificación urbana, de la red vial, y en el diseño y operación de las vías.

Correctivo: donde se realiza la corrección o ratificación de factores viales que ya están generando siniestros. Los accidentes que se dan de manera dispersa a lo largo de una vía son abordados mediante la "gestión segura de tránsito", mientras que en los puntos negros que son los que abarcan la mayor cantidad de siniestros se aplica medidas de ingeniería de bajo costo (22).

Las medidas ingenieriles de bajo costo son herramientas técnicamente planificadas y aplicadas en sitios específicos de una vía que fueron identificados como conflictivos, dichas herramientas son destinadas a la reducción del número de siniestros a través de una corrección y mejora de la infraestructura vial. Dichas medidas son eficaces pese a su relativa simplicidad, entre estas se encuentra la colocación de atenuadores de velocidad, despeje de obstáculos visuales (rameado de árboles frondosos), manteamiento de la pintura de la señalización horizontal, colocación de isletas en intersecciones, entre otras (23).

La elección y posterior aplicación de las medidas ingenieriles de bajo costo depende de varios factores que deben ser previamente analizados, pudiendo ser estos: el clima y el tipo de material que se dispone. Las medidas destinadas a la reducción de siniestros en los puntos críticos han sido sintetizadas de manera grupal como se muestra a continuación:

i. A través de la fotogrametría se comprobó el desgaste que presenta la señalización horizontal en los puntos críticos, motivo por el cual la colocación de pintura nueva es el requerimiento 
con el que se debe inicial.

ii. La implementación de nueva señalización horizontal como es el caso de líneas logarítmicas acompañadas de tachas tienen como objetivo influir en la reducción de velocidad la misma que se ha comprobado que es elevada en los puntos críticos.

iii. En casos en los que la pendiente no permite la instalación de reductores de velocidad físicos, la opción viable recae en reductores virtuales los cuales generan un impacto visual a los conductores provocando una reducción de velocidad.

iv. El atenuador de impactos es un dispositivo físico que ha demostrado su eficacia al momento de encauzar un vehículo a la vía en caso de choque, o de atenuar el impacto evitando así lesiones graves en los usuarios del automotor, por estas razones y al comprobar que en el punto crítico N3 se generan impactos es de imperiosa necesidad la instalación de este dispositivo (24).

\section{Énfasis en caminar, montar bicicleta.}

En el Ecuador la Nueva Ley Orgánica de Transporte Terrestre Tránsito y Seguridad Vial, establece en el Art. 204 que uno de los derechos de los ciclistas es disponer de vías de circulación

privilegiada dentro de las ciudades y en las carreteras, como ciclovías y espacios similares, ratificando esto en el Art. 209 donde se instituye que las entidades municipales deberán hacer estudios para incorporar en el casco urbano vías nuevas de circulación y lugares destinados para estacionamiento de bicicletas para facilitar la masificación de este medio de transporte.

En el contexto de la actual pandemia por el COVID-19 que ha obligado a todas las personas a mantener el denominado distanciamiento social la Organización Mundial de la Salud establece que es necesario aprovechar aquel que ofrecen los modos de transporte activos en los que la probabilidad de contraer el virus es del $0.1 \%$, frente a las condiciones de encierro que generan los transportes públicos donde la probabilidad de contagio asciende a un 67\%. Del mismo modo los medios transporten como la bicicleta permiten un reforzamiento del sistema inmunológico de los usuarios reduciendo el riesgo de contagio.

Por todo lo planteado anteriormente se propone acercar a la avenida Mariscal Sucre a una movilidad sostenible haciendo que el vehículo privado pierda su protagonismo y permitiendo así que el peatón pueda movilizarse de manera más segura y saludable y en armonía con el medio ambiente ya sea a pie, o bicicleta generando una movilidad sostenible (25).

\section{CONCLUSIONES}

La siniestralidad en el Ecuador ha experimentado un descenso anual del 9\% desde el año 2015 hasta el 2019, mientras que debido a las restricciones de movilidad impuestas en el territorio nacional como medida para controlar el avance del Covid- 19 durante el 2020 el número de siniestros se redujo en un $37 \%$, esta reducción se ve refleja en la también disminución de lesionados producto de los mismos, lo que no sucede con las víctimas fatales en donde su número presenta un ascenso del $2 \%$ anual, permitiendo concluir que aunque el

número de siniestros se han reducido no sucede lo mismo con la gravedad que estos acontecen, $y$ para que un país sea considerado como referente en seguridad vial la Organización Mundial de la Salud toma a la reducción de mortalidad por siniestros de tránsito como indicador principal.

La importancia de la determinación de los índices de accidentalidad radica en que estos son instrumentos que permiten sintetizar aspectos importantes de los siniestros, en el caso del tramo estudiado de la Avenida Mariscal Sucre se calculó los índices a partir del número total de accidentes registrados en la vía y de los atribuidos a los conductores y peatones, a través de estos parámetros fue posible conocer que cada 100 accidentes, en el 2018, 79 fueron causados por el conductor, mientras que en el 2019 el número haciende a 89; para esa misma cantidad de accidentes 6 fueron provocados por los peatones en el 2018 mientras que para el año 2019 el valor del índice se reduce a 4 , esto permite concluir que el comportamiento 
vial de los peatones ha mejorado durante el año 2019 pues su participación directa en siniestros viales se ha reducido, cosa que no ocurre con los conductores pues se evidencia el incremento de siniestros donde estos han influido.

A partir del cálculo del índice de accidentabilidad con respecto a la población que reside en los barrios ubicados a lo largo del tramo estudiado, es posible llegar a la conclusión que los siniestros de tránsito ocurridos en la Av. Mariscal Sucre, representan el 53.70\% de los suscitados a nivel cantonal, comprobando así que efectivamente la Av. Mariscal Sucre es la que más siniestralidad posee en el Distrito Metropolitano de Quito.

Si bien la avenida Mariscal Sucre fue diseñada como una vía perimetral, el incremento de la población a su alrededor ha sido tal que en la actualidad es catalogada como una Vía Semi
Expresa Arterial según la ordenanza municipal $\mathrm{N}^{\circ} 0432$, siendo este cambio es una de las causas principales para que se produzca el alto número de siniestros tal y como se ha observado en otras vías del país, en donde el cambio en el uso de la vía ha sido el factor común para la ocurrencia de accidentes.

Una vez realizado el respectivo análisis estadístico de los siniestros que tuvieron lugar a lo largo del tramo estudiado se obtuvo como resultado cinco Puntos Críticos o Negros. De dichos puntos es posible extraer como conclusión que su porcentaje de INCREMENTO - REDUCCIÓN de siniestros es inverso al de los puntos no críticos, como se muestra a continuación en el gráfico, es decir en los PC, existe una baja reducción y elevado incremento de siniestros, mientras que en los PNC la reducción es alta y el incremento bajo.

$\mathrm{R}$ eferencias

1. World Health Organization, Global status report on road safety 2018, Geneva: WHO, 2018.

2. Organización Mundial de la Salud, Informe sobre la situación mundial de la seguridad vial 2015, Ginebra: OMS, 2015.

3. Organización Mundial de la Salud, Control de la Velocidad, Ginebra: OMS, 2017.

4. D. Soria, A. Pinto, M. Ponce de Leon y E. Café, Estrategia de seguirdad vial: Contribuyendo a disminuir la brecha de siniestralidad en América Latina y el Caribe: Resultados del primer quinquenio y plan de acción 2016-2020, Washington DC: Banco Interamericano de Desarrollo, 2017. 5. World Health Organization, «Global Plan for the Decade of Action for Road Safety 20112020,» [Internet]. [citado: 10 Noviembre 2020]. Disponible en: https://www.who.int/roadsafety/ decade_of_acti on/plan/plan_english.pdf?ua=1.

6. D. Medina, M. Medina y C. Escobar, Accidentes de tránsito Rescate in situ, Quito: Ediciones Médicas EDIMEC, 2019.

7. A. Congacha, J. Barba, L. Palacios y J. Delgado, «Caracterización de los siniestros viales en el Ecuador,» NOVASINERGIA, vol. II, n 2, pp. 17-29, 2019.

8. J. Campon, Manual de Investigación de Siniestros Viales, Madrid: Ministerio del Interior-Dirección General de Tránsito, 2017.

9. P. Giscard, Phytosociologie de la securite el des risquesd accidents chez le conducteurs de voiture, Paris: Janvier Juin, 1967.

10. J. Dextre, M. Pirota, C. Tobasso, J. Bermudez y G. Anibal, Vías humanas: Un enfoque multidiciplinario y humano de la seguridad vial., Lima: Fondo Editorial Pontifica Universidad Católica del Perú, 2008.

11. A. Gomez, M. Russo y P. Suasnavas, «Caracterización de la Mortalidad por Accidentes de 2015,» Ciencimerica, vol. I, no 5, pp. 22-32, 2016.

12. Instituto de Salud Global de Barcelona, «ISGlobal,» [Internet]. [citado 11 Noviembre 2020]; Disponible en: https://www.isglobal.org/documents/10179/794 3094/6_ISGlobal+COVID19+y+movilidad+ES.pdf/428d93ba-d4b2-4042-9f24-ec5c17bb8dc5. 
13. El Comercio, «El Comercio,» [Internet]. 29 Septiembre 2020. [citado 11 Noviembre 2020]. Disponible en: https://www.elcomercio.com/blogs/informe- judicial/pandemia-vuelven-fatídicosaccidentes-transito.html.

14. D. Guaman, Diagnostico del problema de congestión vehicular en el intercambiador Ferndande Salvador: Intersección Av. Mariscal Sucre, Av. Fernadez Salvador y Calle Melchor de Valdez, Quito: Pontifica Universidad Catolica del Ecuador, 2016.

15. Dirección de ingeniería de tránsito y seguridad vial, «Número mensual de accidentes suscitados en los principales ejes viales del DMQ,» Agencia Metropolitana de Tránsito, Quito, 2020.

16. Federación Internacional de Sociedades de la Cruz Roja y de la Media Luna Roja, Guía práctica de seguridad vial, Suiza: Global Road Safety Partnership, 2007.

17. Centro de Experimentación y Seguridad Vial Colombia S.A, «CESVI COLOMBIA,» [Internet]. 26 Octubre 2016. [citado19 Noviembre 2020]. Disponible en: http://www.revistaautocrash. com/identificar- puntos-negros-reduce-la-accidentalidad/.

18. S. Cecchini, Indicadores sociales en América Latina y el Caribe, Santiago de Chile: Cepal: División de Estadística y Proyecciones Económicas , 2005.

19. R. Cal y Mayor y J. Cardenas, Ingenieria de Tránsito, Mexico D.F: Alfaomega Grupo Editor, 2007.

20. A. S. f. P. a. R. S. ASPRS, «The Imaging and Geospatial Information Society,» [Internet]. 6 Octubre 2020. Disponible en: https://www.asprs.org/organization/what-is- asprs.html.

21. Agencia Nacional de Transito, «Agencia Nacional de Transito,» Agencia Nacional de Transito, [Internet]. 5 Enero 2021. Disponible en: https://www.ant.gob.ec/index.php/estadisticas. [Último acceso: 28 Marzo 2020].

22. CONASET, Hacia Vías Urbanas más Seguras: Medidas correctivas de bajo costo aplicadas en ciudades Chilenas, Santiago: Comisión Nacional de Seguridad de Tránsito: Secretaría Ejecutiva, 2005.

23. A. Guillermo, Mejoras en la seguridad vial con medidas de bajo costo, Lima: Pontífica Unversidad Catolica de Perú, 2018.

24. Pan American Health Organization, Status of Road Safety in the Region of the Americas, Washington, D.C: PAHO, 2019.

25. A. Gómez, V. Orbe y Y. Campos, «Morbilidad y mortalidad por accidentes de tránsito según componentes temporales, Ecuador,» Killkana Salud y Bienestar, vol. III, n 1, pp. 9-16, 2019. 